\title{
Evaluation of hypolipidemic and hepatoprotective effects of ethanolic extract of cleome brachycarpa on albino rabbits
}

\begin{abstract}
Increased Cholesterol is one of the main culprits responsible for cardiovascular diseases. The present study was designed to evaluate the effect of ethanolic extract of Cleome brachycarpa on cholesterol and hepatic parameters and to evaluate whether its use can be helpful in treatment of hepatic and cardiovascular diseases.

The study was conducted on albino rabbits weighing $1000 \mathrm{gms}-1600 \mathrm{gms}$. The animals were administered $300 \mathrm{mg} / \mathrm{kg}$ of ethanolic extract of Cleome brachycarpa that was further diluted in Dimethyl sulfoxide and dose was adjusted in $\mathrm{ml}$ based on weight of animals. After 7 days dosing animals blood was drawn by cardiac puncture and Lipid profile and Liver function tests were done.

Our study showed that Ethanolic extract of Cleome brachycarpa possess significant hypolipidemic effects.It also lowers Total and Direct Bilirubin and Alkaline Phosphatase but elevates SGPT, SGOT and Gamma-GT. Cleome brachycarpa can be used in hyperlipidemia but monitoring of liver enzymes may be required during therapy.
\end{abstract}

Volume 5 Issue $6-2017$

\author{
Sana Sarfaraz, Rahila Najam, lqbal Azhar, \\ Shadab Ahmed, Ghulam Sarwar \\ Department of Pharmacology, Faculty of Pharmacy, Jinnah \\ University for women, Pakistan
}

\begin{abstract}
Correspondence: Sana Sarfaraz, Department of Pharmacology, Faculty of Pharmacy, Jinnah University for women, Karachi-74600, Pakistan, Email sana.sarfraz@live.com
\end{abstract}

Received: August 03, 2017| Published: August 29, 2017

Keywords: alkaline phosphatase, bilirubin, cholesterol, cleome brachycarpa, gammaGT, hyperlipidemia

Abbreviations: ALP, alkaline phosphate; SGOT, serum glutamic oxaloacetic transaminases; SGPT, serum glutamic pyruvic transaminase; GGT, gamma glutamyl transferase; TB, total bilirubin; LDL, low- density lipoprotein; HDL, high- density lipoprotein; LCF, lipid clearing factor; DMSO, dimethyl sulfoxide; VLDL, very lowdensity lipoprotein; GPT, glutamic-pyruvic transaminase

\section{Introduction}

Hyperlipidemia is defined as abnormal increased levels of lipoproteins or lipids in the blood. ${ }^{1}$ Hyperlipidemia can lead to number of cardiovascular disorders mostly due to artherosclerosis. Cardiovascular diseases are the most prevalent cause of death all around the world. ${ }^{2}$ Since the beginning of human civilization, plants have been used for treatment of different ailments. Phytochemicals are synthesized by plants which are chemical compounds. ${ }^{3}$ Plants which contain phytochemicals when consumed by humans as a source of food are helpful in treating different diseases. ${ }^{4}$

Plants had been used for healthcare and medicinal purposes long before it was recorded in history. As early as 3000 BC Egyptian papyrus and ancient Chinese writing describe medicinal uses of plant. ${ }^{5}$ The use of herbs to treat different diseases is very common in under developed third world countries because it is cheaper and safer than modern allopathic medicine. According to survey conducted by World Health Organization $80 \%$ of the population of some African and Asian countries still prefer to use herbal medicine. ${ }^{6}$

Cleome includes species which have ecological, ethno botanical and medicinal value. Cleome belongs to a small family of flowering plants and is the largest genus comprising of about 180-200 species. ${ }^{7}$ Cleome comprises of herbaceous annual or perennial plants and shrubs. Genus Cleome was classified under family Capparidaceae however recently on the basis of DNA studies it has been placed under family Cleomaceae. ${ }^{8}$ Traditionally leaf paste of cleome has been effective in headache. Cleome gynandra's leaf juice is effective in earache and skin diseases. ${ }^{9}$
Boiled leaves of Cleome serrulata are used in black paint preparation. Rubifacient and counter-irritant properties are found in species like Cleome viscose, Cleome gynandra and Cleome chelidonii. They are also used for rheumatism. ${ }^{10}$

Cleome brachycarpa is mostly distributed in tropical and subtropical regions. ${ }^{11}$ Through spectroscopic analysis of Cleome brachycarpa, Cabralealactone, Ursolic acid and new trinortriterpenoid dilactone deacetoxybrachycarpone has been isolated. ${ }^{12}$ A new triterpenoid Cleocarbpone was also isolated from Cleome brachycarpa which has double oxygen function at C-24 and belongs to dammarane series. ${ }^{13}$ Cleome brachycarpa has shown to possess numerous beneficial effects. The plant possesses anti-bacterial and anti-fungal properties and is thought to be useful appetizer and effective in abdominal discomfort. ${ }^{14}$ The ethanolic extract of Cleome brachycarpa possesses anxiolytic properties. ${ }^{15}$ and also has positive effect on memory. ${ }^{16}$ The leaves also possess anti-inflammatory properties, useful in rheumatism and are also effective in leucoderma and scabies. ${ }^{17}$ The objective of the above study was to evaluate the effect of ethanolic extract of Cleome brachycarpa on lipid profile and on hepatic parameters in healthy rabbits.

\section{Materials and methods}

The plant Cleome brachycarpa was provided by Dr. Iqbal Azhar from Department of Pharmacognosy University of Karachi.

\section{Extraction of plant}

The plant was first washed with water to reduce microbial load. The whole plant of Cleome brachycarpa was cut into small pieces and dried at $50^{\circ} \mathrm{C}$, and then it was powdered. Next this powdered material was macerated with $95 \%$ ethanol for 3 days. It was then filtered and reduced to dryness under pressure. The process of maceration was repeated twice and then dried using (vacuum) evaporator. 


\section{Animals selected}

For biochemical screening albino rabbits of either sex weighing 1000 - 1600 grams were selected. Biochemical variations produced in rabbits and humans are comparatively similar therefore rabbits were selected for these tests. ${ }^{18}$ The rabbits were equally divided into 2 groups, each containing 10 animals. First group served as Control, second was given Cleome brachycarpa. Animals were handled as per specifications provided in Helsinki Resolution 1964 and study was approved by our Board of Advanced Studies and Research vide Resol. No,09 Dated:20-04-2011\& 22-04-2011.

\section{Dosing regimen}

First group was taken as control and given DMSO ( Dimethyl sulfoxide) (same calculated $\mathrm{ml}$ as other groups) orally. Second group was given $300 \mathrm{mg} / \mathrm{kg}$ Cleome brachycarpa, the dose was adjusted based on weight of rabbits. Standard solution of $1500 \mathrm{mg} / 10 \mathrm{ml}$ was prepared in DMSO and it was administered orally in $\mathrm{ml}$ by serial dilution method once daily for 7 days.

Sample Collection: $7 \mathrm{ml}$ of blood samples were drawn from rabbits after 7 day dosing by cardiac puncture. $5 \mathrm{ml}$ blood is taken in gel tube for lipid profile and other biochemical analysis.

\section{Estimation of lipid profile}

Clotted blood samples were centrifuged for 15 minutes at 3000rpm to separate serum using Humalyzer 3000, semi-automatic chemistry analyzer model \# 16700 (Human Germany). The parameters were analyzed within 3 hours of sample collection using standard kits supplied by Human.

\section{Estimation of cholesterol}

Cholesterol oxidase/peroxidase aminophenazone(CHOD-PAP method) which involves enzymatic colorimetric test for cholesterol with lipid clearing factor (LCF) was used to determine cholesterol in serum. ${ }^{19}$

\section{Estimation of HDL and LDL-cholesterol}

Mostly laboratories use selective precipitation for removing VLDL and LDL, whereas supernatant fraction contains HDL which is enzymatically measured. ${ }^{20}$ We used Human cholesterol test kit with precipitant, standard and HDL- cholesterol using Friedwald Method. LDL was also determined using Friedwald Method. ${ }^{21}$

\section{Estimation of liver function test}

Using standard reagent kits of Human Germany, liver enzymes (SGPT and SGOT) were measured after centrifugation and obtaining serum.

\section{Estimation of SGPT and SGOT}

For GPT estimation liquid UV test
method Alanine aminotransferase was used. ${ }^{22}$ By Glutamic Oxaloacetic Transaminase (GOT) Aspartate amino Transferase (ASAT) International Federation of Clinical Chemistry (IFCC) mod liquid UV test the SGOT test was performed. ${ }^{22}$

\section{Estimation of alkaline phosphatase (ALP)}

Using standard kits supplied by Human (HUMALYZER 3000) ALP was analyzed. ${ }^{23}$

\section{Estimation of gamma- glutamyl transferase $(\gamma-$ GT)}

Using colorimetric method $\gamma$-GT was estimated in the serum based on Szasz Method. ${ }^{24}$

\section{Estimation of Bilirubin}

By photometric test total bilirubin and Direct Bilirubin was measured in serum..$^{25}$

\section{Results}

By taking mean of all the values they are compared with means of control and Cleome brachycarpa and by student significance T -test the significance of difference between means are determined. A value of $p<0.05$ is considered significant, $p<0.001$ as more significant and $\mathrm{p}<0.0001$ as highly significant. By Alcarz and Jimenez method all statistical procedures have been performed. ${ }^{26}$

\section{Discussion}

Herbal preparations have been used since ancient times as a source of medicinal agent because of their therapeutic efficacy, low cost and safety. Cleome brachycarpa belonging to family Cleomaceae has not been vastly investigated although it has been shown to possess a number of therapeutic effects.

The major contributing factors in the pathogenesis of atherosclerosis and resulting cardiovascular diseases are increased plasma lipids. ${ }^{27}$ Cholesterol is main reason of unanticipated progression and development of atheroma plaque. ${ }^{28}$ Past studies indicate that high cholesterol prompts atherosclerosis and heart diseases as well as diabetes mellitus and cancerous development. Lowering the cholesterol level has an impact on prostrate tumors i.e it impedes their development. ${ }^{29}$

There are also reports that LDL and HDL levels are more particular and sensitive biochemical markers of cardiovascular disease and HDL also serves to protect against advancement of atherosclerosis. ${ }^{30}$ Table 1 $\& 2$ shows effect of ethanolic extract of Cleome brachycarpa on lipid profile. Our results show highly significant decrease in cholesterol and LDL cholesterol $\mathrm{p}<0.0001$ while there was no significant effect on HDL cholesterol $\mathrm{p}=$ IS. Saponins have been shown to possess hypocholesterolemic properties. $^{31}$ They act by decreasing the intestinal absorption of cholesterol; they are also thought to interfere with the cholesterol metabolism by interfering with circulating bile acids. ${ }^{32}$ Ursolic acid present in cleome also possesses lipid lowering and cardio-protective properties. ${ }^{33}$

Liver is the focus of biotransformation and metabolism of huge number of drugs and foreign agents thus hepatic damage is potential effect of many drugs. ${ }^{34}$ Genuine underlying ailments can be found by rise of hepatic enzymes for example alanine transaminase and aspartate transaminase. ${ }^{35} \mathrm{ALT}$ is likewise signified as serum glutamate pyruvate transaminase and AST can be additionally called as serum glutamate oxaloacetate transaminase.

Hepatocytes contain the enzyme SGPT. This enzyme is leaked into the blood when these cells are damaged, where it is measured. SGPT is extremely elevated in acute liver diseases. SGOT is comparable to SGPT since it is also present in hepatocytes. It is elevated in acute liver damage, additionally it is present in erythrocytes, cardiac and skeletal muscle and not particular to liver. ${ }^{36}$ Alkaline phosphatase is specific in cells lining biliary duct. ALP levels elevate in infiltrative diseases of liver. Gamma GT is present in cell membranes of many tissues of bile duct, gall bladder, heart, brain and kidney etc. ${ }^{37}$ 
Table I Effect of Ethanolic Extract of Cleome brachycarpa on Lipid Profile

\begin{tabular}{llll}
\hline Groups & Cholestrol $(\mathrm{mg} / \mathrm{dl})$ Mean \pm SD & HDL $(\mathbf{m g} / \mathbf{d l})$ Mean \pm SD & LDL (mg/dl) Mean \pm SD \\
Control & $41.20 \pm 4.08$ & $6.0 \pm 0.816$ & $36.7 \pm 1.16$ \\
Cleome brachycarpa & $|4.3 \pm 2.3|^{* * *}$ & $6.30 \pm 1.16$ & $4.9 \pm 0.876 * * *$ \\
\hline
\end{tabular}

Values are mean \pm S.D.

$\mathrm{n}=10=$ number of animals.

$* * * \mathrm{p}<0.000 \mathrm{I}=$ highly significant.

IS = insignificant difference.

Table 2 Effect of Ethanolic Extract of Cleome brachycarpa on Hepatic Parameters

\begin{tabular}{|c|c|c|c|c|c|c|}
\hline Groups & $\begin{array}{l}\text { Total Bilirubin } \\
\text { (mg/dl) } \\
\text { Mean } \pm \text { SD }\end{array}$ & $\begin{array}{l}\text { Direct Bilirubin } \\
(\mathrm{mg} / \mathrm{dl}) \\
\text { Mean } \pm \text { SD }\end{array}$ & $\begin{array}{l}\text { SGPT }(\mu / l) \\
\text { Mean } \pm \text { SD }\end{array}$ & $\begin{array}{l}\text { SGOT }(\mu / l) \\
\text { Mean } \pm \text { SD }\end{array}$ & $\begin{array}{l}\text { Gamma GT }(\mu / \mathrm{l}) \\
\text { Mean } \pm \text { SD }\end{array}$ & $\begin{array}{l}\text { Alkaline phosphatase }(\mu / l) \\
\text { Mean } \pm \text { SD }\end{array}$ \\
\hline \multirow{2}{*}{$\begin{array}{l}\text { Control } \\
\text { Cleome } \\
\text { brachycarpa }\end{array}$} & $0.40 \pm 0.008$ & $0.066 \pm 0.005$ & $42.10 \pm 0.876$ & $48.5 \pm 1.08$ & $4.3 \pm 0.823$ & $27.2 \pm 0.7$ \\
\hline & $0.24 I \pm 0.026 * * *$ & $0.016 \pm 0.005 * * *$ & $337 \pm 2.54 * * *$ & $253.9 \pm 2.85^{* * *}$ & $15.3 \pm 1.89 * * *$ & $25.3 \pm 0.53$ \\
\hline
\end{tabular}

Values are mean \pm S.D.

$\mathrm{n}=10=$ number of animals.

$*_{\mathrm{p}}<0.05=$ significant.

$* * * \mathrm{p}<0.000 \mathrm{I}=$ highly significant.

IS = insignificant difference.

Normal heme catabolism results in yellow breakdown product called Bilirubin. It has been found in plants too. It is excreted in bile and urine. ${ }^{38}$ Total or direct bilirubin is usually estimated to monitor gall bladder or liver problems..$^{39}$ Cleome brachycarpa highly significantly increases SGPT, SGOT and $\gamma$-GT levels $\mathrm{p}<0.0001$ showing liver damage or hepatotoxic effects. It highly significantly reduces $\mathrm{p}<0.0001$ total and direct bilirubin and has no effect on alkaline phosphatase as such. The hepatotoxic effect may be due to deacetoxybrachycarpone or cabralealactone but further work needs to be done to evaluate its effects.

\section{Conclusion}

On the basis of our study we can conclude that Cleome brachycarpa possesses hypolipidemic effects and could be beneficial in patients suffering from cardiovascular disease as but dose reduction needs to be done along with monitoring of liver parameters to avoid hepatotoxic effects.

\section{Acknowledgments}

None.

\section{Conflicts of Interset}

None.

\section{References}

1. www.freedictionary.com

2. Global Atlas on Cardiovascular Disease Prevention and Control.

3. Tapsell LC, Hemphill I, Cobiac L, et al. Health benefits of herbs and spices: the past, the present, the future. Med J Aust. 2006;185(4):4-24.

4. Rui Hai Liu. Health benefits of fruits and vegetables are from additive and synergistic combinations of phytochemicals. The American Journal of Clinical Nutrition. 2003;78(3):517-520.

5. Moquin.B, Blackman MR, Mitty E, et al. Complementary and alternative medicine (CAM). Geriatric Nursing. 2009;30(3):196-203.
6. Fabricant DS, Farnsworth NR. The value of plants used in traditional medicine for drug discovery. Environ Health Perspect. 2001;109(1):6975 .

7. Aparadh VT, Karadge BA. Infrared Spectroscopic Studies in Some Cleome species. Life Science Feed. 2001;1:5-7.

8. Cooke T. Flora of the Presidency of Bombay Vol II (Publ). Botanical Survey of India, Culcutta, India, 1903. p. 42-43.

9. James A Chweya, Nameus A Mnzava. Cat's Whiskers. Cleome Gynandra L. 1997. p. 23.

10. Sungwarl S, Supanee P. Biological activity of Cleome spp.extracts against the rice weevil Sitophilus oryza L. Agriculture Sci J. 2006;37(5):232-235.

11. Raghavan RS. Capparaceae. In: Sharma BD \& Balakrishnan NP (Eds.), Flora of India, Botanical Survey of India, Howrah, India, 1993. p. 248335

12. Viqar UA, Khisal AA. Deacetoxybrachycarpone a trinortriterpenoid from Cleome brachycarpa. Phytochem. 1986;26(1):315-316.

13. Ahmad VU, Sabiha Qazi, Zia NB. Cleocarpone, a triterpenoid from Cleome brachycarpa. Journal of Phytochemistry. 1990;29(2):670-672.

14. Atiq-ur- Rahman M, Jaber S, Mossa Mansour S, et al. Medicinal plant diversity in the flora of Saudi Arabia 1: a report on seven plant families. Fitoterapia. 2004;75(2):149-161.

15. Sana Sarfaraz, Rahila Najam, Iqbal AzharAnxiolytic and CNS depressant effects of ethanolic extract of cleome brachycarpa revealed after neuropharmacological screening. World Journal of Pharmaceutical Sciences. 2004;7: 605-610.

16. Sana Sarfaraz, Rahila Najam, Iqbal Azhar. Memory Boosting effects of Cleome brachycarpa: alternative approach to treat dementia? World Journal of Pharmacy and Pharmaceutical Sciences. 2014;3(7):1750 1757.

17. Khare CP. Indian Medicinal Plants: An Illustrated Dictionary Cleome Brachycarpa. 2007. p: 1-157.

18. Irana C, Kazimier K, Leopold Andreze JK. Blood serum protein in experimental chronic liver injury in rabbits. Pathol Pol. 1797;30(1):7188. 
19. Lumb PJ, Slavin BM. Determination of serum cholesterol concentration in the presence of ascorbate. J Clin Pathol. 1993;46(3):283-284.

20. Warnick GR, Peter WD. National cholesterol education program recommendations for measurement of high-density lipoprotein cholesterol; Executive Summary. Clin Chem. 1995;41(10):1427-1433.

21. Friedewald WT, Levy RI, Friedrickson DS. Estimation of concentration of low-density lipoprotein cholesterol in plasma, without use of the preparative ultracentrifuge. Clin Chem. 1972;18(6):499-502.

22. Klin Z, Chem Klin. Biochemistry. 1972;10:182.

23. Schuman G, Klauke R. New IFCC reference procedures for the determination of catalytic activity concentrations of five enzymes in serum: Preliminary upper reference limits obtained in hospital subjects. Clin Chem Acta. 2003;327(1-2):69-79.

24. Szasz G. Reaction-rate method for $\gamma$-glutamyl transferase activity in serum. Clin Chem. 1976;22(12):2051-2055.

25. Jendrassik L, Grof P. Colorimetric method of determination of bilirubin Bio Chemz. 1938;297:81-82.

26. Emili García-Berthou, Carles Alcaraz. Incongruence between test statistics and $\mathrm{P}$ values in medical papers. BMC Med Res Methodol. 2004;4:13.

27. Sliskovic DR, White AD. Therapeutic potential of ACAT inhibitors as lipid lowering and anti-atherosclerotic agents. Trends Pharmacol Sci. 1991;12(5):194-199.

28. www.nhs.uk/Conditions/Atherosclerosis. Retrieved on 09/11/2015.

29. Solomon KR, Pelton K, Boucher K, et al. Ezetimibe is an inhibitor of Tumor angiogenesis. Am J Pathol. 2009;174(3):1017-1026.
30. Guyton AC, Hall JE. Textbook of Medical Physiology. (11th edn), WB Saunders Company, USA. 2006.

31. Rupasinghe HP, Jackson CJ, Poysa V, et al. Soyasapogenol A and B distribution in soybean (Glycine max) in relation to seed physiology, genetic variability and growing location. J Agric Food Chem. 2003;51(20):5888-5894.

32. Lalita Maria Calabria. The isolation and characterization of Triterpene Saponins. Pro Quest LLC UMI, 2008. p. 30.

33. Senthil S, Sridevi M, Pugalendi KV. Protective effect of ursolic acid against myocardial ischemia induced by isoproterenol in rats. Toxicol Mech Methods. 2007;17(1):57-65.

34. Lee WM. Drug-induced hepatotoxicity. N Engl J Med. 1995;333:11181127.

35. Giboney PT. Mildly elevated liver transaminase levels in asymptomatic patient. Am Fam Physician. 2005;71(6):1105-1110.

36. Shuvaev VV, Christofidou-Solomidou M, Bhora F, et al. Targeted detoxification of selected reactive oxygen species in vascular endothelium. J Pharmacol Exp Ther. 2009;331(2):401-411.

37. Goldberg DM. Structural, functional and clinical aspects of Gamma glutamyl transferase. CRC Crit Rev Clin Lab Sci. 1980;12(1):1-58.

38. Pirone C, Martin J, Quirke E, et al. The animal pigment Bilirubin discovered in plants. $J$ Am Chem Soc. 2009;131(8):2830.

39. Berk PD, Korenblat KM. Approach to patient with Jaundice or abnormal liver test results. In: Goldman $\mathrm{L}$ et al., editors. Cecil Medicine, (23rd edn), Saunders Elsevier, Philadelphia, USA. 2007. 